\title{
Exploring the promising potential of high permeation vesicle - mediated localised transdermal delivery of docetaxel in breast cancer to overcome the limitations of systemic chemotherapy
}

Minal Bathara, Tushar Date, Dasharath Chaudhari, Rohan Ghadi, Kaushik Kuche, Sanyog Jain*

Centre for Pharmaceutical Nanotechnology, Department of Pharmaceutics, National Institute of Pharmaceutical Education and Research (NIPER), S.A.S. Nagar (Mohali), Sector 67, Punjab - 160062, India

*Corresponding author: Dr. Sanyog Jain

Email: sanyogjain@ niper.ac.in, sanyogjain@ rediffmail.com

Tel: +91172-2292055, Fax: +91172-2214692

\section{Characterization of HPV loaded gel}

$1.5 \% \mathrm{w} / \mathrm{v}$ solution of Carbopol $980 \mathrm{NF}$ was used as a gelling matrix considering the therapeutic safety, regulatory approval, optimal rheological properties (good spreadability, ease of removal and non-stickiness), ability to form firm gel structure along with maintaining the stability of HPVs.

\subsection{Determination of $\mathbf{p H}$}

The $\mathrm{pH}$ of the gel was slightly acidic with average value of $5.8 \pm 0.11$.

\subsection{Determination of rheology}

The figure S1 shows rheological behaviour after application of varying shear rate values. As the shear rate increases the shear stress also increased simultaneously. The rheological profiles of free DTX, SCOPE gel, liposomal gel and HPV's loaded gel showed acceptable flow properties for purpose of topical application. 


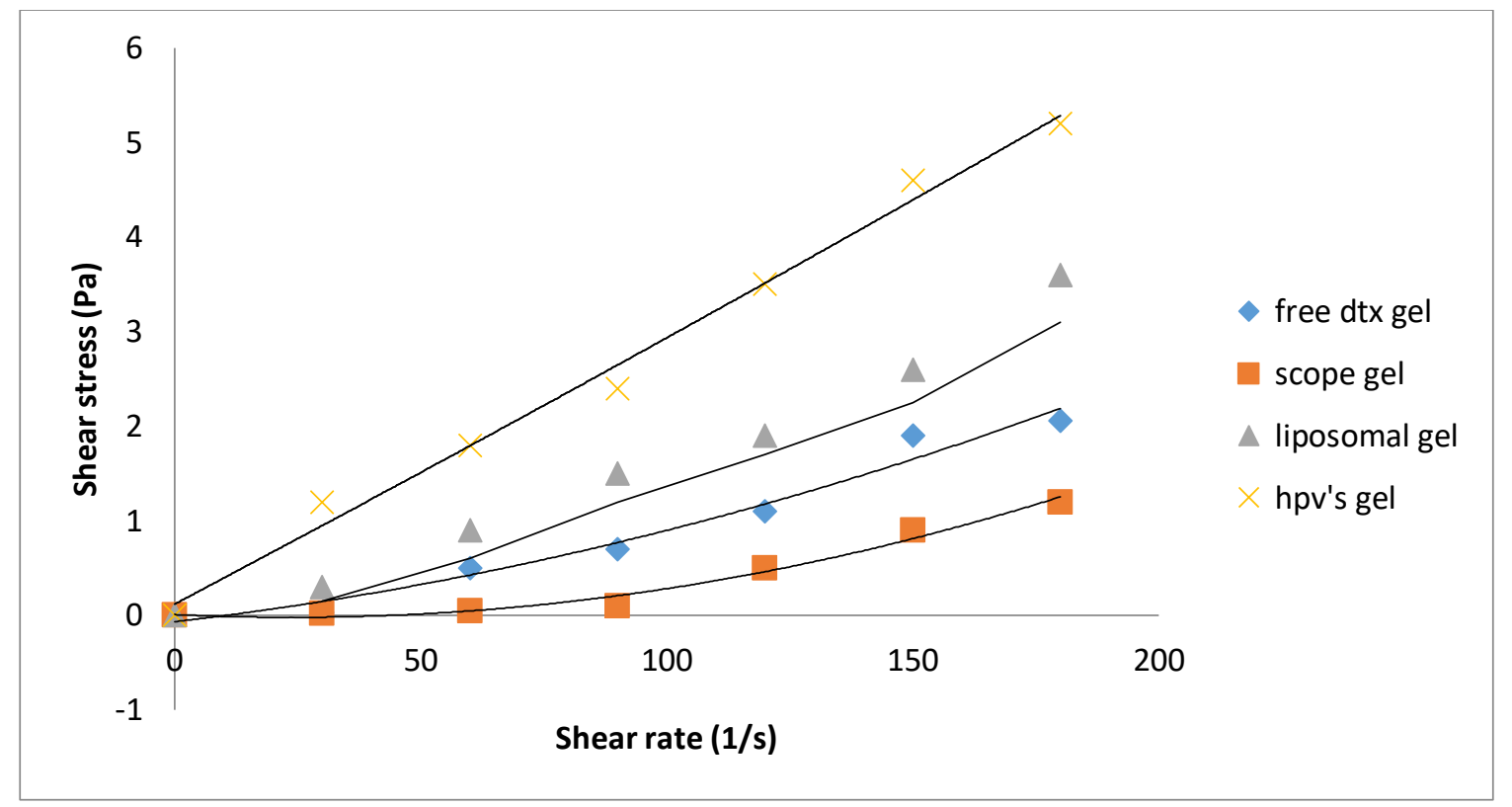

Figure S1: Rheology of gel based DTX formulations

\subsection{Spreadability study}

In spreadability studies change in spreading area was observed as a function of change in weight and these studies were conducted using acrylic plate method. The spredability of the gel increased with increase in weight, which implies spreading of gel can be enhanced by rubbing the gel onto the skin (Figure S2).

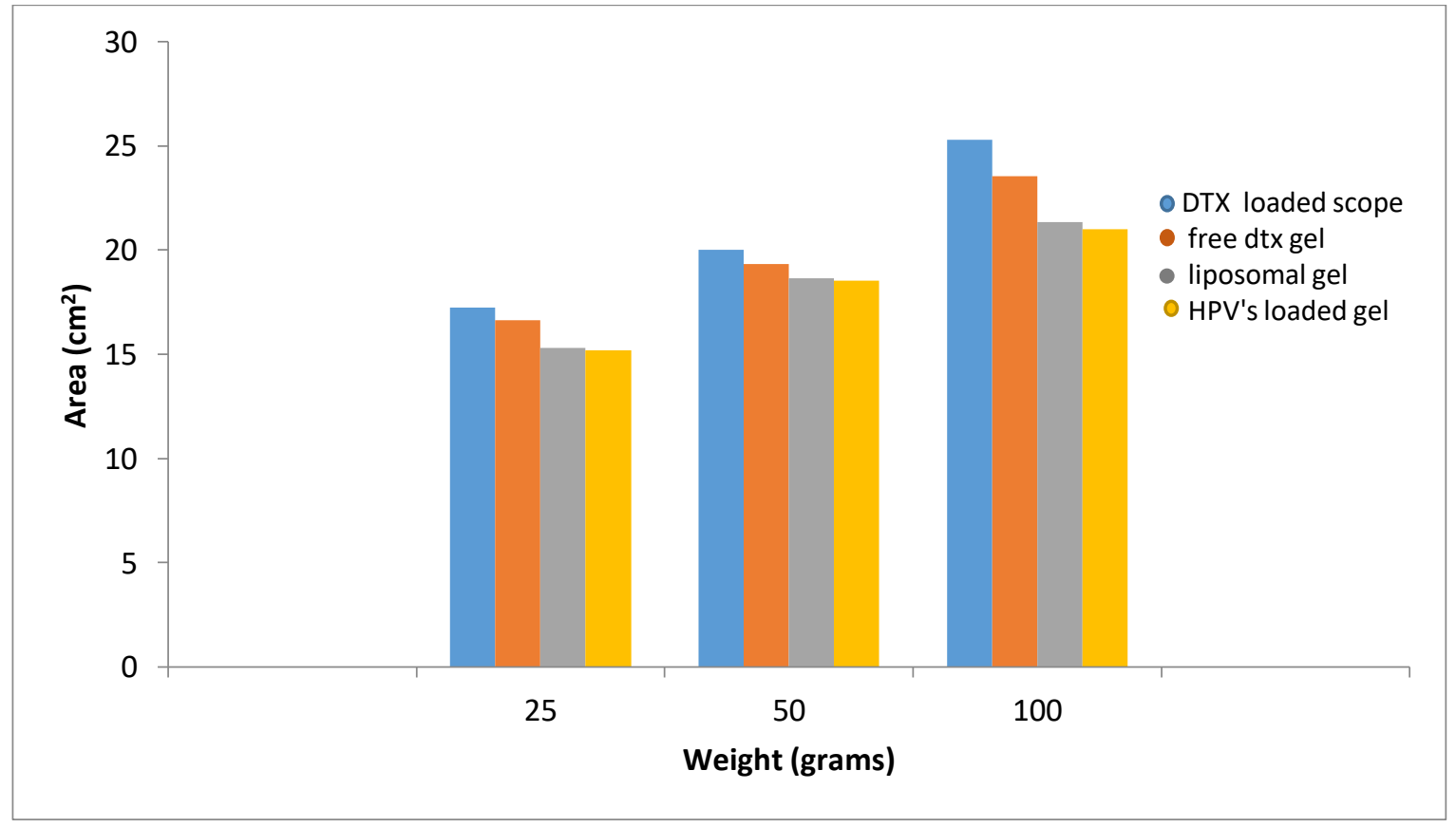

Figure S2: Spreadability of gel based formulations as a function of area improvement 


\section{Quantification results of EDS analysis}

Table S1: Quantification of elemental composition of HPVs through EDS method

\begin{tabular}{|c|c|c|c|c|}
\hline Element & Weight \% & Atomic \% & $\begin{array}{c}\text { Detector } \\
\text { correction }\end{array}$ & k-factor \\
\hline $\mathrm{C}$ & 86.26 & 91.00 & 0.26 & 3.940 \\
\hline $\mathrm{O}$ & 7.68 & 6.08 & 0.49 & 1.974 \\
\hline $\mathrm{Na}$ & 3.32 & 1.83 & 0.81 & 1.171 \\
\hline $\mathrm{S}$ & 2.73 & 1.07 & 0.93 & 1.021 \\
\hline
\end{tabular}

Correction method used - Thickness 